\title{
Outcome of Medical versus Surgical Methods in Second Trimester Abortion
}

\author{
Lama $S^{1}$, Chhetri $S^{2}$ \\ ${ }^{1}$ Department of Obstetrics and Gynaecology, Patan Academy of Health Science, Nepal, ${ }^{2}$ Department of Obstetrics and \\ Gynaecology, BP Koirala Institute of Health Sciences, Dharan.
}

Received: February 12, 2015 ; Accepted: September 15, 2015

Aims: This study aimed to assess the effectiveness of medical versus the surgical methods and to determine the outcome of both the methods with respect to complications like incomplete abortion, bleeding and sepsis.

Methods: This study was conducted at BP Koirala Institute of Health Sciences (BPKIHS). Total of 80 patients, 40 in each group were enrolled in the study. For medical abortion group, Mifepristone $200 \mathrm{mg}$ orally followed by Misoprostol $400 \mathrm{mcg}$ vaginally were given until the patient expelled the fetus. In surgical group, cervical priming was done with Misoprostol followed by dilatation and evacuation. The outcome of both medical and surgical abortions were compared in terms of amount of blood loss and associated complications like retained placenta and sepsis.

Results: The overall complications were more in the medical group with $11.25 \% \mathrm{vs} 2.5 \%$ in the surgical group (p value $=0.02$ ), with higher incidence of retained placenta (8 vs 0$)$ and a higher amount of blood loss $(129.20+/-20.4 \mathrm{ml} \mathrm{vs} 70.89+/-11.2 \mathrm{ml}$, $\mathrm{p}$ value $<0.001)$ requiring blood transfusion.

Conclusions: This study demonstrated that the surgical method is a more effective and safer procedure as compared to medical method. The complication rates were lower and it was also more cost effective.

Keywords: abortion; blood loss; dilatation and evacuation; second trimester.

\section{INTRODUCTION}

World Health organization (WHO) estimates that about $25 \%$ of all pregnancies worldwide end in induced abortion, that is approximate 15 million each year. ${ }^{1}$ More than half of these abortions are performed under unsafe conditions, resulting in high maternal mortality ratio especially in developing countries like Nepal. More than 100,000 unwanted pregnancies each day, or about 36-53 million each year ends in induced abortion. Induced abortions are performed either medically or surgically before the time of fetal viability. Medical abortion is one that ends pregnancy by taking medications while surgical abortion is one that ends pregnancy by evacuating the uterus with surgical instruments.

Both medical and surgical methods of abortions are associated with complications. According to a study done by Autry et al, overall complications were more in patients that underwent medical abortion $(29 \%$ vs

\section{CORRESPONDENCE}

Dr Sushma Lama

Department of Obstetrics and Gynaecology, Patan academy of Health Sciences, Nepal

Email: drsushmalama@gmail.com

Phone: +977-9849497223
$4 \% ; \mathrm{p}<0.001){ }^{2}$ Another study done by Grimes et $\mathrm{al}^{3}$ showed that the incidence of minor complications such as hemorrhage (not requiring transfusion), febrile morbidity, cervico-vaginal trauma was lower in patients in surgical group. They also concluded that dilatation and evacuation is the safest method of second trimester abortion. In this study we attempted to compare the effectiveness and outcome of medical versus surgical methods in second trimester abortion.

\section{METHODS}

This study was a randomized control trial of women presenting to department of obstetrics and gynaecology at BP Koirala Institute of Health Sciences (BPKIHS) with gestational age of 12-18 weeks based on last menstrual period (LMP), clinical feature and ultrasonography for abortion. This study was conducted from July 2011 to July 2012 after getting approval from BPKIHS ethics committee.

The sample size for medical vs surgical was 40 women in each group. The inclusion criteria for the study were pregnancies from 12-18 weeks determined by LMP, clinical features and Ultrasonography, singleton pregnancy and (Hemoglobin) $\mathrm{Hb}>$ or $=$ $10 \mathrm{gm} / \mathrm{dl}$.

Exclusion criteria were twin pregnancy, pregnancy 
$>18$ weeks, previous two caesarean sections, previous uterine scar such as myomectomy, patients with diseases like chronic adrenal failure, asthma, bronchitis, genetic diseases, prolong use of steroids, allergic to Mifepristone or Misoprostol. Patients who had already taken Mifepristone or Misoprostol on her own were also excluded in this study.

Computer generated randomization was done on all women who met the inclusion criteria then counseling was done for the selected patients to initiate the study. Informed written consent was taken from each of the subjects as well for the study. For medical abortion group, Mifepristone $200 \mathrm{mg}$ once orally followed by Misoprostol $400 \mathrm{mcg}$ once vaginally after 36 hours were given until the patient expelled the fetus. Misoprostol $400 \mathrm{mcg}$ vaginally was given maximum of 5 doses 4 hours apart. If a patient doesn't expel a fetus after the $5^{\text {th }}$ dose, it was considered as a failed abortion, and was excluded from the study. In surgical group, cervical priming was done with one dose of Misoprostol 400mcg followed by dilatation and evacuation (D\&E).

In medical abortion, frequency of Misoprostol, duration of expulsion of fetus and placenta from the start of Misoprostol, amount of blood loss, and any associated complications like incomplete abortion, excessive hemorrhage, infection or rupture uterus were monitored and scored.

In surgical group, frequency of Misoprostol, duration of procedure, amount of blood loss, incomplete abortion, injury to cervix and vagina, uterine perforation and septic abortions were monitored and scored.

All the patients in both groups were called for follow up after 1 week of medical or surgical procedure. Performa was filled up, data were entered in MSExcel file and were analyzed by SPSS software.

\section{RESULTS}

Eighty patients were enrolled in this study, their demographic information at enrollment is shown in Table 1. Majority of the recruits were between ages of 20-34 years. The minimum age was 15 years and maximum was 44 years. Most of the women were illiterate and among them majority were housewives. Majority of the patients were multigravida, upto gravid 9.
Table 1. Distribution of age, literacy and parity.

\begin{tabular}{|lll|}
\hline Characteristics & Categories & Frequency \\
\hline \multirow{2}{*}{ Age in years } & $<20$ & $9(11.25 \%)$ \\
& $20-34$ & $55(68.75 \%)$ \\
& $>34$ & $16(20.0 \%)$ \\
Education & Illiterate & $54(67.5 \%)$ \\
& Literate & $26(22.5 \%)$ \\
Gravida & Primi & $24(30.0 \%)$ \\
& Multi & $56(70 \%)$ \\
\hline
\end{tabular}

After the medical or surgical procedure, majority of the patients used pills as the contraceptive method; 22 patients had taken Depoprovera and $15 \mathrm{had}$ undergone minilap (Table 2).

Table 2. Distribution of contraception.

\begin{tabular}{|lll|}
\hline Characteristics & Categories & Frequency \\
\hline \multirow{3}{*}{ Methods } & Pills & $40(50.0 \%)$ \\
& Depot & $22(27.5 \%)$ \\
& Minilap & $15(18.75 \%)$ \\
& Others & $3(3.75 \%)$ \\
\hline
\end{tabular}

In medical group, all the patients received Mifepristone. Four patients expelled fetus with Mifepristone only and all were intra-uterine fetal death (IUFD). Thirty-six patients required 1 dose of Misoprostol, 28 patients required 2 doses, 17 patients required 3 doses, 10 patients required 4 doses and 6 patients required 5 doses of Misoprostol (Table 3 ).

Table 3. Distribution Surgical Vs Medical method of abortion.

\begin{tabular}{|lll|}
\hline Treatment & Categories & Frequency \\
\hline Surgical & D and E & $40(100 \%)$ \\
& A & $40(100 \%)$ \\
& B & $36(90.0 \%)$ \\
Medical & C & $28(70.0 \%)$ \\
& D & $17(42.5 \%)$ \\
& E & $10(25.0 \%)$ \\
& F & $6(12.50 \%)$ \\
\hline
\end{tabular}

As shown in Table 4, in medical group, complications were seen in 9 patients, one patient had a heavy per vaginal (PV) bleeding, and 8 had retained placenta. In surgical group, 2 patients had heavy PV bleeding and 1 had incomplete abortion.

Blood transfusion was required for 5 patients in 
medical group and 1 patient in surgical group. Blood loss was seen more in medical group $>/=500 \mathrm{ml} \mathrm{p}$ value was highly significant $<0.001$ (Table 4 ).

Table 4. Distribution of Complications of the procedure.

\begin{tabular}{|c|c|c|c|c|}
\hline & Category & $\begin{array}{l}\text { Group } \\
\text { Medical }\end{array}$ & Surgical & p-value \\
\hline \multirow{5}{*}{ Complication } & No & 31 & 38 & \multirow{5}{*}{0.023} \\
\hline & Yes & 9 & 2 & \\
\hline & Bleeding & 1 & 2 & \\
\hline & Incomplete & 0 & 1 & \\
\hline & $\begin{array}{l}\text { Retained } \\
\text { Placenta }\end{array}$ & 8 & 0 & \\
\hline \multirow{2}{*}{$\begin{array}{l}\text { Complication } \\
\text { treatment }\end{array}$} & No & 31 & 38 & \multirow{2}{*}{0.023} \\
\hline & Yes & 9 & 2 & \\
\hline \multirow[b]{2}{*}{ Transfusion } & No & 35 & 39 & \multirow[b]{2}{*}{0.200} \\
\hline & Yes & 5 & 1 & \\
\hline \multirow{3}{*}{$\begin{array}{l}\text { Blood loss } \\
\text { in } \mathrm{ml}\end{array}$} & $\leq 100$ & 21 & 26 & \multirow{3}{*}{-} \\
\hline & $101-499$ & 14 & 14 & \\
\hline & $\geq 500$ & 5 & 0 & \\
\hline $\begin{array}{l}\text { Mean Blood } \\
\text { loss } \pm \text { SD }\end{array}$ & & $\begin{array}{l}129.20 \pm \\
20.4\end{array}$ & $\begin{array}{l}70.89 \pm \\
11.2 \\
\end{array}$ & $<0.001$ \\
\hline
\end{tabular}

\section{DISCUSSION}

Our study showed that in overall, complications were seen more in medical group $11.25 \%$ compared to that of surgical group, which had 2.5\% $(\mathrm{p}<0.023)$. The complications included heavy PV bleeding, retained placenta, and incomplete abortion.

Similar study done by Grimes et al, showed that the incidence of minor complications like hemorrhage, febrile morbidity, and cervical-vaginal trauma were lower in patients in surgical group. ${ }^{4}$ Another study done by Autry et $\mathrm{al}^{2}$, showed more complications in medical abortion group ( $29 \%$ vs 45$)$ compared to that of their surgical group. However, Cabezas's study indicated that in spite of higher proportion of secondary effects, there was satisfaction with medical method because medical method is non-invasive and non-violent method.

In our study, when medical and surgical groups were compared, the duration needed for expulsion was greater in medical group, which lengthened the hospitalization period. Five patents required blood transfusion medical while one patient required it in surgical group. Surgical methods required 30 minutes for the procedure to complete and were done in outpatient basis, and majority of the patients were discharged on the same day. In agreement with our study, a study done by E W Freeman et al showed that surgical procedures required less than 30 minutes to complete and patients were able to return home on the same day if done by an experienced clinician. ${ }^{5}$

However, a study done by Stephen et al, showed that the complications of D\&E included 4 genital tract laceration, 2 cases of excessive bleeding, 2 post-op admissions for antibiotic administrations for endometritis, 1 for observation after an excessive bleeding, 1 admission for severe nausea associated with general anesthesia. Also, one patient had amniotic fluid embolism with DIC, requiring transfusion of blood and clotting factors. Another patient had uterine perforation requiring exploratory laparotomy and blood transfusion. ${ }^{6}$

In contrary to the study by Stephen et al, ${ }^{6}$ our study showed that 2 patients had complications in the surgical group; 1 patient had an excessive bleeding requiring a blood transfusion and another patient had an incomplete abortion, which required check curettage. There were no cases of genital tract lacerations, sepsis or uterine perforations as complications.

In many parts of the world D\&E is the standard method for termination of pregnancies of over 13 weeks of gestation and is considered to be a safe and an effective option when undertaken by specialist practitioners with appropriate experience. ${ }^{7}$ Even though the safety and efficacy of D\&E for termination of second-trimester pregnancy has been found to be superior to medical methods in this review, some practitioners find it very distressing to perform this procedure at an advanced stage of gestation. ${ }^{8}$ Whereas the Royal College of Obstetricians and Gynaecologists recommends medical abortion with mifepristone followed by a prostaglandin as a safe and effective method for second-trimester abortion. ${ }^{7}$ Uterine rupture occurs rarely in second-trimester medical terminations of pregnancy, but providers should be aware of this risk. ${ }^{9}$ 


\section{CONCLUSIONS}

In this study, we concluded that surgical abortion in second trimester is a safer procedure than the medical procedure. This study also confirmed that there was lower complication associated with second trimester abortion in surgical method compared to that of medical method.

\section{DISCLOSURE}

The authors report no conflicts of interest in this work. No violation of human rights and safety.

Funding: Nil

\section{REFERENCES}

1. WHO. Abortion. A Tabulation of Available Data on the Frequency and Mortality of Unsafe Abortion. Geneva : WHO; 1993.

2. Autry AM, Hayes EC, Jacobson GF, Kirby RS. A comparison of medical induction and dilation and evacuation for secondtrimester abortion. Am J Obstet Gynecol. 2002;187:393-7.

3. Grimes DA, Schulz KF. Mid-trimester abortion by dilatation and evacuation: a safe and practical alternative. N Engl J Med. 1977;296:1145.

4. Grimes DA, Schulz KF, Cates W Jr, Tyler CW Jr. Morbidity and mortality from second-trimester abortions. J Rep Med. 1985;30:505-14.

5. Freeman EW. Abortion: subjective attitudes and feelings. Fam Planning Perspect. 1978; 10.
6. Stephen LP, Ling FW, Meyers CM. Dilation and evacuation for second-trimester genetic pregnancy termination: update on a reliable and preferable method. Am J Gynecol Health. 1991;5:30-3.

7. Royal College of Obstetricians and Gynaecologists. The care of women requesting induced abortion. London: RCOG Press; 2004.

8. Lalitkumar S, Bygdeman M, Gemzell-Danielsson K. Midtrimester induced abortion: a review. Hum Reprod Update. 2007;13:37-52.

9. Phillips K, Berry C, Mathers AM. Uterine rupture during second trimester termination of pregnancy using mifepristone and a prostaglandin. Eur J Obstet Gynecol Reprod Biol. 1996;65:175-6 